\title{
\begin{tabular}{|l|l|}
\hline Journal of Zoology & ZSL \\
\hline
\end{tabular}
}

\section{Understanding the coexistence of competing raptors by Markov chain analysis enhances conservation of vulnerable species}

\begin{tabular}{|r|l|}
\hline Journal: & Journal of Zoology \\
\hline Manuscript ID & JZO-10-15-OM-328.R1 \\
\hline Manuscript Type: & Original Manuscript \\
\hline Date Submitted by the Author: & 03-Feb-2016 \\
\hline Complete List of Authors: & $\begin{array}{l}\text { Sarà, Maurizio; University of Palermo, Department of Biological, Chemical } \\
\text { and Pharmaceutical Sciences and Technologies } \\
\text { Mascara, r; Fondo Siciliano per la Natura } \\
\text { Lopez, Pascual; Universitat de Valencia Institut Cavanilles de Biodiversitat i } \\
\text { Biologia Evolutiva, Terrestrial Vertebrates Group }\end{array}$ \\
\hline Keywords: & $\begin{array}{l}\text { Mediterranean habitats, Perturbation analysis, Species coexistence, Markov } \\
\text { chain, Raptor competition, Falcons }\end{array}$ \\
\hline
\end{tabular}


Understanding the coexistence of competing raptors by Markov chain analysis enhances 2 conservation of vulnerable species

7 1. Section of Animal Biology, Department of Biological, Chemical and Pharmaceutical

8 Sciences and Technologies, University of Palermo, Via Archirafi 18, Palermo, Italy.

9 2. Fondo Siciliano per la Natura, Via Popolo, 6, Niscemi, Italy.

3. Cavanilles Institute of Biodiversity and Evolutionary Biology, Terrestrial Vertebrates

11 Group, University of Valencia, C/ Catedrático José Beltrán 2, 46980, Paterna, Valencia, 12 Spain.

14 \$ Corresponding author: Maurizio Sarà, maurizio.sara@unipa.it

15 Running head: Markov chain analysis of competing raptors

17 Abstract. Understanding ecological interactions among protected species is crucial for 18 correct management to avoid conflicting outcomes of conservation planning. The occurrence 19 of a superior competitor may drive the exclusion of a subordinate contestant, as in Sicily where the largest European population of the lanner falcon is declining because of potentially competing with the peregrine falcon. We measured the coexistence of these two ecologically

22 equivalent species through null models and randomisation algorithms on body sizes and 23 ecological niche traits. Lanners and peregrines are morphologically very similar (Hutchinson 24 ratios < 1.3 ) and show $99 \%$ diet overlap, and both of these results predict competitive 25 exclusion. In contrast, their use of diverse cliff substrates for breeding in different times of the season would predict coexistence. To compare these two mutually excluding hypotheses,

27 we examined the pattern of interspecific transitions in 88 sites that were studied for 14 years 28 (2000-2013) using a Markov chain occupancy state model, and checked the sensitivity and 29 elasticity of the community structure to changes in transition probabilities. During the study 30 period, 1144 territorial transitions occurred in peregrine and lanner territories, and the 31 Markov chains were predicted to converge to a stable equilibrium in 2065. Markovian 
1 analysis suggested that temporal and spatial segregation of habitat during reproduction might

2 prevail over anatomical specialisation for hunting and diet, allowing species coexistence,

3 despite the prediction that peregrines will outnumber the lanners in future projections. Our

4 approach combining niche-overlap analysis and species occupancy modelling led to practical

5 information about conservation options available for the threatened lanner. Lanners are very

6 sensitive to site abandonment, and measures increasing adult persistence in occupied

7 territories could be more rewarding than those encouraging juvenile dispersal and

8 colonisation of new sites.

9

10 Keywords: Competition, Lanner, Markov chain, Mediterranean habitats, Peregrine,

11 Perturbation analysis, Raptor ecology, Species coexistence.

12 


\section{$1 \quad$ Introduction}

2 Niche theory predicts that coexisting species should differ in ecological, morphological or 3 behavioural characteristics in a way that minimises competition (Hutchinson, 1959). The 4 ability to compete is usually different among species, and ecological interactions occurring 5 for limited resources are asymmetrical, with the dominant species reducing the fitness of 6 subordinate ones by constraining their utilisation of preferred resources (e.g. Campobello, 7 Hare \& Sarà, 2015). The latter is typical of interference competition (Amarasekare, 2002), 8 which will have different long-term effects depending on its strength, ranging from stable 9 coexistence to competitive exclusion (Tokeshi, 1998).

10 Many drivers, such as body size and social system (e.g. García \& Arroyo, 2002), human 11 disturbance and the harshness of environmental gradients (e.g. Moreno-Rueda et al., 2009; 12 Miller et al., 2012), and more recently, invasive species (e.g. Santulli et al., 2014), have been 13 claimed to alter resource availability and in turn the outcome of competitive interactions. In 14 general, the higher the niche-overlap value between two species, the less likely it is that there 15 will be long-term population coexistence (Krüger, 2002a; 2002b). In addition, phylogenetic 16 niche conservatism has been suggested to enhance the likelihood of interspecific competition 17 (Losos, 2008).

18 The importance of competition has been emphasised at high trophic levels (Hakkarainen et $19 a l ., 2004)$. Since most raptors are long-lived territorial species and show great fidelity to their 20 breeding areas (Newton, 1979), the habitat around their nest and features of the nest site itself 21 are closely associated with breeding success (Sarà, Campobello \& Zanca, 2012; Amato et al., 22 2014) and hence influence fitness (Bosakowski, Smith \& Speiser, 1992). As a consequence, 23 when habitat conditions limit the breeding space of cavity-nesting Falco species, the need for 24 favourable nesting habitats may drive intense intraspecific or interspecific competition (e.g. 25 Brambilla et al., 2010). 
1 Conditions regulating species coexistence are not only relevant per se, but are more

2 stimulating when the species in question are of conservation concern. This is particularly

3 important when the occurrence of a superior competitor may lead to competitive exclusion or

4 may limit the density of a subordinate and threatened competitor (López-López et al., 2004;

5 Oro et al., 2009). Current implementation of environmental policies and laws generally

6 ignore interspecific effects (Soulé et al., 2003), which may in turn generate unexpected and

7 conflicting consequences on the practical effects of conservation management actions (e.g.

8 Thirgood et al., 2000; Roemer \& Wayne, 2003).

9 Checking territorial occupancy is a reliable method for the assessment of spatiotemporal

10 variations in territory quality of raptors (Sergio \& Newton, 2003). Since most processes

11 affecting species interactions are stochastic (e.g. human disturbance) and the interpretation of

12 results based on static approaches may be misleading (Miller et al., 2012), a valid dynamic

13 approach to the investigation of community interactions is the estimation of site transition

14 probabilities that determine species occupancy by using Markov chain models (Hill, Witman

15 \& Caswell 2002; 2004). Markov chains (MC) were first used in animal ecology to model

16 successional changes (Waggoner \& Stephens, 1970; Tanner, Hughes \& Connell, 1994), and

17 they are now attracting attention for application in the study of population dynamics of

18 vulnerable species (López-López et al., 2009; Martin et al., 2009a; Jiménez-Franco, Martínez

19 \& Calvo, 2011).

20 In this paper, we study two falcon species - the peregrine (Falco peregrinus brookei) and the

21 lanner (F. biarmicus feldeggii) - that live sympatrically in the Mediterranean island of Sicily

22 (Italy). All members in the Falconidae form a monophyletic group (Fuchs, Johnson \&

23 Mindell, 2015) and although peregrine and lanner are not sister species, they have high

24 morphological similarity in their anatomical specialisations for hunting. Both species show

25 territorial behaviour, usually nest on cliffs and need open habitats for hunting, and so many 
1 populations are sympatric in steppe-like habitats (Ferguson-Lees \& Christie, 2001). Birds

2 caught in aerial chases form the total of peregrine prey and most of the lanner prey biomass.

3 The lanner falcon can also feed on a variable frequency of reptiles, small mammals and

4 insects, although these confer a low biomass contribution (Ferguson-Lees \& Christie, 2001;

5 Andreotti \& Leonardi, 2007). For these reasons, a high degree of phylogenetic niche 6 conservatism (Losos, 2008) might be expected and this in turn would drive the potential 7 interference between coexisting populations of the two falcons.

8 Importantly both species are protected, and included in Annex I of the 2009/147/EC Bird 9 Directive. They are listed in the 'least concern' category by the IUCN (2011) global 10 assessment. Nonetheless, while the peregrine is still a least-concern species in the European 11 Union, the lanner has an unfavourable conservation status, due to its small and declining 12 populations and dispersal range, and has been listed as a vulnerable species in the Italian Red 13 list (Birdlife International, 2004; Peronace et al., 2012).

14 Sicily hosts the largest European population of F. b. feldeggii (Andreotti \& Leonardi, 2007).

15 Recently, spatial analysis of lanner habitat preferences in Sicily suggested that the alteration 16 of traditional agro-ecosystems might enhance interference competition with the peregrine and 17 limit its occupancy (Sarà, 2014), thus reinforcing hypotheses of competitive interactions 18 between the two species (Sarà, 2008).

19 As the coexistence of ecologically equivalent species is rare in islands due to their smaller 20 size and larger isolation with respect to continents (Gotelli \& McCabe, 2002), a careful 21 quantitative investigation of the ecological relationships between these two potentially 22 competing species is necessary to avoid the failure of conservation planning (Sergio \& 23 Hiraldo, 2008) and to design specific management actions aimed at mitigating the lanner 24 population decline in its Mediterranean core range. 
1 In particular, the aims of this paper were to: i) investigate the potential competitive effects of

2 the peregrine on lanner occupancy of breeding territories by performing a MC occupancy

3 state model on the patterns of interspecific site transitions; ii) examine through perturbation

4 analysis the sensitivity and elasticity of the community structure to changes in transition

5 probabilities; iii) simulate the effects of potential management strategies aimed at increasing

6 the number of territories occupied by the most vulnerable lanner and to assess their impact on

7 long-term population dynamics.

8

$9 \quad$ Materials and Methods

10 Study area

11 Sicily, the largest Mediterranean island, was selected as a study area representative of the

12 lanner falcon range. It covers $25,832 \mathrm{~km}^{2}$ and is the largest ( $8.6 \%$ of the national surface) and

13 one of the most populated (197 inhabitants per $\mathrm{km}^{2}$ ) administrative regions of Italy. Almost

$1424.4 \%$ of the territory is mountainous, $61.4 \%$ is composed of highlands, and $14.2 \%$ of the

15 surface is lowland. Natural vegetation has been greatly reduced by human influence, and

16 forests occupy only $8 \%$ of the territory, mostly in the northern region. There is considerable

17 habitat heterogeneity in the hilly and flat inland areas, where arable land, fodder, vineyards

18 and olive orchards alternate with woodlots of non-native species (Pinus spp. and Eucalyptus

19 spp.), natural evergreen woodlands (Quercus spp.), Mediterranean xeric grasslands and shrub

20 vegetation. The climate is Mediterranean, but annual precipitation is highly variable and

21 increases with elevation.

22

23 Population monitoring

24 Accurate occupancy datasets of lanners and peregrines in Sicily were available from past

25 surveys carried out for the third Atlas of Breeding Birds of Sicily (AA.VV., 2008), and from 
1 other specific surveys (Andreotti \& Leonardi, 2007; Sarà, 2008). From these datasets, we

2 selected a large area of sympatry of the two falcons that covered $10,200 \mathrm{~km}^{2}$. In this area,

3 with the aid of collaborators that are well versed in the identification and ecology of falcons,

4 we intensively searched and monitored falcon territories, gathering information on 168 sites

5 occupied by falcons. As not all sites were checked every year, we restricted our analysis to 88

6 territories from which we were able to gather complete occupancy data during the 2000-2013

7 breeding seasons. For the purposes of this study, the occupancy of both falcons was

8 expressed in terms of territorial pairs, irrespective of breeding output. We considered as a

9 'territory' a site, often an entire cliff, plus a portion of the surrounding land defended

10 exclusively by each species. Therefore, by definition, both species could not coexist in the

11 same territory. All selected territories were visited at least three times during each breeding

12 season, from late January to mid June, to assess occupancy. During the study period, 75

13 territories were occupied in at least one year, by territorial pairs of falcons, while 13 remained

14 vacant. These latter represented a sample of sites where records (killings and/or observations

15 of transient adults and juveniles) were reported in the past (Authors and B. Massa,

16 unpublished data). Special care (i.e. extra visits) was taken to ensure that territorial pairs were

17 effectively not present in vacant territories or to detect where they moved in case of site 18 desertion. Observations were made using 10x42 binoculars and 20x60 telescopes on clear 19 days and from 200-500 m away from the nesting cliffs to avoid disturbance.

\section{Assessing the degree of competition between lanner and peregrine}

22 We quantified the overlap of body sizes and some traits (see Appendix and Tables in 23 Supporting Information) of the ecological niche between lanner and peregrine by using null 24 models and randomisation algorithms (Gotelli \& Graves, 1996), provided in Ecosim 7.0 25 software (Gotelli \& Entsminger, 2001), in order to better understand the ecological 
1 equivalence of both falcons (see Appendix S1 for rationale and computational details).

2 Results (see Table S1 and S2) obtained from our quantitative approach allowed us to set two 3 mutually exclusive hypotheses and related predictions as follows: a) if equally high

4 anatomical specialisation for hunting and diet exists, then phylogenetic niche conservatism

5 would predict the competitive exclusion of one species from Sicily; b) if spatial and temporal

6 segregation of the breeding sites exists, then niche partitioning would predict the possible

7 coexistence of the two species in the island.

8 Then, using the transition probabilities recorded at 88 falcon sites monitored over a period of

914 years, we tested the two predictions by means of Markov chain analysis (MCA).

\section{Markov chain analysis}

12 We calculated the frequency with which territories used by each species in a given year were 13 re-occupied by the same species in the following year, usurped by the other, or abandoned, as 14 well as the frequency with which empty territories were colonised by either lanners or 15 peregrines, or remained unoccupied. These frequencies were used to calculate the transition 16 probabilities and to build 13 transition matrices of a first-order Markov model for the study 17 period (2000-2013). We started with the number of present territories of each species and 18 those vacant in 2000 as the stage vector, and considered time steps of one year. According to 19 our definition of territory and to previous MCA that estimated community interactions (e.g. 20 Tanner et al., 1994; Hill et al., 2004), we assumed that all territories could be potentially 21 occupied by both species and vacant territories could be colonised in the future. This 22 prerequisite assumption of the study seems reasonable because according to our field 23 observations and those of Di Vittorio et al. (2015), cliff replacements between both species as 24 well as colonization of vacant territories were recorded. 
1 A finite-state $\mathrm{MC}$ reflects a stochastic process independent of time, in which the probability

2 of moving from one state to the next (fate at time $t+1$ ) is conditional on the present state (fate

3 at time $t$ ). Therefore, we fitted log-linear models on the transition matrices to test whether our

4 data were suitable to build a time-invariant MC (Caswell, 2001; Hill et al., 2002).

\section{$6 \quad$ Perturbation analysis}

7 Sensitivity and elasticity, the two components of perturbation, allow the exploration of how

8 changes in environmental conditions or management practices could affect the dynamics of 9 the community in the long term (Caswell, 2007; Green, Bailey \& Nichols 2011). We 10 explored the effects of changes in transition probabilities of the lanner, which has the worse 11 conservation status, in order to identify management strategies that may improve the 12 likelihood of population persistence. To that end, we explored the effects of increasing the 13 probability of: a) persistence of lanner territories (coded as L-L, which reads lanner to 14 lanner), thus reflecting decisions that decrease lanner adult mortality and/or discourage the 15 abandonment of its occupied territories; b) replacement from territories occupied by 16 peregrines to those occupied by lanner (P-L); c) transition from vacant territories to those 17 occupied by lanners (E-L), thus modelling a potential scenario in which the mortality of 18 juvenile lanners decreases, and/or lanner colonisation of new territories is encouraged. 19 Changes were modelled by iteratively increasing the probability of transition of the variable 20 of interest to 1\%, 2.5\% and 5\% (Caswell, 2001; López-López et al., 2009). One of the 21 essential properties of Markov chains is that they require column totals to sum to 1 , and so it 22 is not possible to modify only one variable while holding all others constant (Caswell, 2001).

23 Hence, the two transition probabilities of compensatory variables in the same column were 24 modified iteratively by decreasing their respective value by the same quantity as that of the 25 transition of interest and keeping the third constant. For instance a $1 \%$ increase in the E-L 
1 transition probability was compensated by a $1 \%$ decrease in the E-P transition probability

2 while keeping the E-E transition probability constant. This allowed us to assess the relative 3 effect of changes in transition probabilities in the population dynamics of the two species 4 given that Markov models converge to a stationary equilibrium in the long term (Caswell, 5 2001; Hill et al., 2004).

6 Transition matrices and the MC were analysed using the package 'markovchain' for $\mathrm{R}$ 7 (Spedicato, 2015). Equilibrium occupancy was calculated according to Martin et al. (2009b) 8 as: $\psi^{*}=$ colonisation/(colonisation + extinction). Statistical significance was set at $P<0.05$.

10 Results

\section{Degree of competition between lanners and peregrines}

12 Preliminary assessment gave information on the potential interactions between the lanners 13 and peregrines living in Sicily (see Table S1 and S2). Morphologically, they are very similar, 14 and in fact the corresponding Hutchinson ratios were lower than 1.3 for size and 2.0 for body 15 weight. Null model analyses of size overlap were not significant values $(P>0.05)$ for each 16 tested trait $(n=6$, Table S1), and thus the tests rejected the Hutchinson hypothesis of 17 minimum morphometric spacing necessary for coexistence. Accordingly, the Pianka's niche18 overlap indexes (PI) for diet (Table S2) indicated the use of identical resources $\left(\mathrm{PI}_{\text {prey_biomass }}=\right.$ 190.999 , and $\mathrm{PI}_{\text {prey_frequency }}=0.922$ ) and the results statistically deviated from those obtained by 20 chance $(P=0.00$ and $P=0.01$, respectively). Consequently, lanners and peregrines living in 21 Sicily show a conspicuous similarity of anatomical traits for hunting (e.g. tarsus and bill 22 sizes, Table S1) in connection with high diet overlap (Table S2). By contrast, nesting site 23 characteristics $\left(\mathrm{PI}_{\text {cliff_height }}=0.242, P=0.921 ; \mathrm{PI}_{\text {cliff_substrate }}=0.839, P=0.446\right)$ and Julian day 24 of laying $(\mathrm{PI}=0.390, P=0.867)$ gave lower Pianka indexes, which were not statistically 
1 different, thus indicating a spatial and temporal segregation of habitat during reproduction 2 that would possibly predict species coexistence.

3

\section{$4 \quad$ Markov chain analysis}

5 A total of 1144 territorial transitions were recorded from 2000 to 2013 in the study area 6 (Table 1), with the lanner showing a median \pm SD of $45.5 \pm 3.8$ occupied territories (min7 max: 36-48) and the peregrine $21.0 \pm 3.9$ occupied territories (min-max: 16-28), while 8 vacant territories were $23.5 \pm 2.3$ (min-max: 19-27). The transition matrix followed the 9 assumptions needed to build a first-order time-invariant MC, as log-linear models showed no 10 significant differences among the annual transition matrices over the study period $\left(\chi^{2}=58.12\right.$, $11 d f=96, P=0.99)$.

12 According to the baseline scenario depicted in Table 1, if current conditions of time13 invariance in transition probabilities persist, the projection of the sampled population in the 1488 sites predicts convergence of the MC to a stable equilibrium in 2065, with 29 lanner pairs, 1537 peregrine pairs and 22 empty sites (Fig. 1). Equilibrium occupancy was $\psi^{*}=0.534$ for the 16 lanner, whereas it was $\psi^{*}=0.607$ for the peregrine. The final stable equilibrium would 17 correspond to a $19 \%$ decrease in lanners, $32 \%$ increase in peregrines and an $8 \%$ decrease in 18 empty sites in 2065 with respect to 2013 (36 lanners, 28 peregrines and 24 empty sites); 19 however, there would be a remarkable $40 \%$ lanner decrease, $131 \%$ peregrine increase and $8 \%$ 20 decrease in empty sites with respect to 2000 . Nonetheless, the key point of the MCA is that a 21 stable coexistence could occur in Sicily, with peregrines outnumbering lanners but without 22 causing their extinction in the long term.

\section{Perturbation analysis}


1 Sensitivity showed diverse scenarios under the different management strategies modelled to 2 increase the likelihood of lanner population persistence (Fig. 2). Measures aimed at 3 increasing territory persistence by lanners ( + LL in Fig. 2) led to the highest number of 4 territories occupied by lanners, thus providing a more efficient approach in terms of 5 population numbers at equilibrium compared with those aimed at lanner replacement of 6 peregrine territories (+PL) and lanner colonisation of empty territories (+EL). Yet lanner 7 persistence deals with two scenarios, the first involving the application of measures to avoid 8 replacement by peregrines (-LP) and the second measures to avoid territory abandonment by 9 lanners (-LE). This latter (Fig. 2) provides the highest numerical reward in terms of lanner 10 territories occupied in the long term, reversing its population decline, while maintaining an 11 acceptable peregrine population (at the $32 \%$ increased level of 2013 ). A relatively low $5 \%$ 12 increase in lanner-to-lanner transition (+LL), compensated by a 5\% decrease in the lanner-to13 empty transition (-LE), would consequently achieve 60 lanner pairs, 28 peregrine pairs and 0 14 empty territories at equilibrium. As shown in Fig. 2, the latter result is a more reasonable 15 figure than that obtained from a $2.5 \%$ or $5 \%$ increase in lanner persistence (+LL), 16 compensated by a similar decrease in the peregrine replacement (-PL).

17 Elasticity provides further insight into the population dynamics of our two-species system 18 (Fig. 3). The highest number of lanner territories was reached in a scenario that modelled an 19 increase in persistence probability compensated by a similar decrease in abandonment 20 probability. The second-best option would be to encourage measures aimed at favouring 21 lanner colonisation of empty territories compensated by a decrease in the colonisation of 22 vacant territories by peregrines. Eventually, the third option aimed at decreasing peregrine 23 persistence in favour of lanner replacement of territories occupied by peregrine, is 24 numerically valid but ecologically implausible. 
1 Discussion

2 Here we used a long-term monitoring scheme to provide information on the site-occupation 3 dynamics of two protected top predators. For our system, interactions of these two large 4 falcons were depicted by a four-state MC model (i.e., colonisation, abandonment, 5 replacement, persistence), which suggested the absence of temporal variations in the 6 transition rates. Although the concepts of equilibrium occupancy obtained by the process of

7 first-order MCA could be considered rather simplistic to express the complexity of species 8 interactions, it should be remarked that the aim of such demographic analysis is not to 9 forecast the real trajectories of population sizes in the future. In fact, the Markovian statistical 10 tool represents a null model against which to compare the consequences of maintaining 11 indefinitely the current conditions with those of alternative conditions (MacKenzie et al., 12 2006; Martin et al., 2009b). This gives a relevant heuristic value that greatly increases the 13 potential to respond to ecological questions and conservation problems (Martin et al., 2009a;

14 Miller et al., 2012).

Degree of competition between lanner and peregrine

17 As expected in members of the same phylogenetic group (Fuchs et al., 2015), Mediterranean 18 populations of peregrine and lanner have very similar body sizes, as occurs for other 19 subspecies such as F. p. minor and F. b. biarmicus (Jenkins, 1995). Interestingly, the wing 20 area and wing loading, which we could not test in our study and that predict significant 21 differences in the hunting abilities of the two South-African falcons (Jenkins, 1995), have 22 size ratios $(\mathrm{HRs} \geq 1.3)$ equivalent to the minimum morphometric spacing necessary for 23 coexistence (Hutchinson, 1959). In addition, Ward, Weigl \& Conroy (2002) showed how the 24 biomechanics of the hind limb is important for resource partitioning and habitat coexistence 25 in raptor guilds. Hence, in our study area, despite the large overlap in size, other functional 
1 traits of the phenotype could be relaxing competition between the two falcons. Accordingly,

2 niche partitioning, with the lanner laying earlier and choosing different cliffs than peregrines

3 (Amato et al., 2014), seems to support a basic coexistence in Sicily that would be enough to

4 overcome the phylogenetic niche conservatism arising from strong morphological similarities

5 and diet overlap.

6 Recent range expansion of one species can have negative effects on the occupancy dynamics

7 of congener species (e.g. Dugger, Anthony \& Andrews, 2011), as in the case of the

8 expanding population of peregrines in Sicily (Sarà, 2008). This latter specie, favoured by

9 anthropogenic habitat alteration is likely increasing its interference competition with the

10 lanner (Sarà, 2014), thus occupying lanners' cliffs (Di Vittorio et al., 2015). This process

11 could in turn break the species' spatial segregation of habitat during reproduction, and the

12 MCA provided novel information about the occupancy dynamics occurring in the study area.

13 In the observed transition matrix, persistence probabilities were higher than interspecific

14 transitions, showing that modelled populations would reach a stable-state equilibrium

15 distribution in the long-term (year 2065), thereby lending support to a possible future

16 coexistence between the two species despite their actual fluctuating demography. Similar to

17 the data found for large eagles (López-López et al., 2009) and forest raptors (Jiménez-Franco

18 et al., 2011) in Spain, this result would suggest that interspecific competition currently has a

19 limited role in Mediterranean communities of raptors. Nonetheless, the real influence of

20 interspecific competition could be masked by anthropogenic factors. For example, human

21 disturbance can drive coexistence by pushing species to less human-populated areas

22 (Moreno-Rueda et al., 2009), or in degraded habitats species may coexist merely because the

23 requirement of vital resources offsets the costs of settling close to a competitor (e.g.

24 Brambilla et al., 2010). 
1 Perturbation analysis and lanner conservation

2 We modelled three scenarios for each of three transition probabilities of two compensatory 3 variables, yielding 18 sensitivity models, which were further scaled to assess the relative 4 effects of sensitivity (elasticity) on the transition probabilities to provide valuable 5 information on which conservation action may be best suited to halt the decline in lanners 6 (Hill et al., 2004). Interestingly, we found the equilibrium occupancy of the lanner to be 7 greater than 0.5 , and so the species seems more sensitive to abandonment than to the 8 colonisation of local sites (Martin et al., 2009b; Green et al., 2011). Translated into 9 conservation practice, this would suggest choosing management strategies that aim to 10 decrease the abandonment of occupied territories and adult mortality, rather than those 11 aimed at encouraging lanner colonisation by improving site quality and/or decreasing 12 juvenile mortality.

13 For example, by simply managing the $5 \%$ of lanner territories to favour site persistence 14 would be enough to reverse the negative population trend in our study area. Besides their 15 poor numerical performances, other options seem unrealistic because it is hard to imagine 16 measures that could encourage lanner colonisation of empty sites (+EL), as well as their 17 replacement of peregrine sites $(+\mathrm{PL})$, without benefiting or impeding peregrine persistence 18 at the same time. Actions aimed at decreasing peregrine persistence and colonisation would 19 require increasing peregrine abandonment rate and decreasing its population size; obviously, 20 neither is acceptable. In summary, from a conservation point of view, management planned 21 to halt site abandonment of the lanner population is also the best compromise with the 22 protected status of the peregrine.

23 Measures able to prevent lanner abandonment should be applied at landscape scale, for 24 example by building a network of priority areas in order to halt degradation of the steppe25 like habitats by agri-environmental schemes (Sarà, 2014). In addition, management 
1 strategies at territory scale should promote persistence rates favouring territorial fidelity

2 through increasing reproductive success (Sergio \& Newton, 2003) and recruitment through

3 proactive actions (Jiménez-Franco et al., 2011), such as: i) minimising illegal nest predation

4 and preventing human disturbance during the breeding period; and ii) reducing unnatural

5 mortality caused by shooting and electrocution of adults during winter and juveniles during

6 post-breeding dispersal.

7

8 Conservation implications

9 In our opinion, the MCA support for coexistence in the long-term should immediately

10 exclude the option of passive conservation, taking into account that our system is framed in

11 fast-changing Mediterranean ecosystems (Sokos et al., 2013). In addition, the insular

12 condition of the populations drives the probabilities of local extinction and colonisation

13 (Ferraz et al., 2007) and is expected to influence the occupancy dynamics of the two falcons

14 in synergy with human disturbance. Hence, managers should not simply 'sit and wait' for the

15 two species to arrange themselves in a new population equilibrium, because transition

16 probabilities could change over time and then model predictions might vary with respect to

17 the original ones, thus underestimating the real ecological process going on. Considering

18 current or future scenarios, measures aimed at halting lanner decline are urgently needed.

20 Acknowledgements

21 We thank S. Riformato, B. Massa and L. Zanca for field support during monitoring and

22 access to their databases. Á. Soutullo provided valuable insight in the main topic of this

23 paper. The Italian Ministry of Education, University and Research (PRIN 2010-2011, 20108

24 TZKHC) supported this project. P. López-López is supported by a "Juan de la Cierva-

25 incorporación" postdoctoral grant of the Spanish Ministry of Science and Innovation 
1 (reference IJCI-2014-19190). We thank two anonymous referees for valuable comments to

2 the manuscript.

\section{References}

5 AA. VV. (2008). Atlante della Biodiversità della Sicilia: Vertebrati terrestri. Palermo: Arpa 6 Sicilia.

Amarasekare, P. (2002). Interference competition and species coexistence. Proc. Royal Soc. Part B Biol. Sciences 269, 2541-2550.

9 Andreotti, A. \& Leonardi, G. (2007). Piano d'azione nazionale per il Lanario (Falco 10 biarmicus feldeggi). Quaderni Conservazione Natura Ministero Ambiente 24, 1-109.

11 Amato, M., Ossino, A., Brogna, A., Cipriano, M., D'Angelo, R., Dipasquale, G., Mannino,

BirdLife International (2004). Birds in Europe. Population estimates, trends and 16 conservation status. Cambridge: BirdLife International.

Bosakowski, T., Smith, D.G. \& Speiser, R. (1992). Niche overlap of two sympatric-nesting hawks Accipiter spp. in the New Jersey-New York highlands. Ecography 15, 358372.

Brambilla, M., Bassi, E., Ceci, C. \& Rubolini, D. (2010). Environmental factors affecting patterns of distribution and co-occurrence of two competing raptor species. Ibis $\mathbf{1 5 2}$, 310-322.

Campobello, D., Hare, J.F. \& Sarà, M. (2015). Social phenotype extended to communities: Expanded multilevel social selection analysis reveals fitness consequences of interspecific interactions. Evolution 69, 916-925.

Caswell, H. (2001). Matrix population models: construction, analysis and interpretation. 2nd edition. Sinauer Associates Inc. Publishers, Sunderland MA.

Caswell, H. (2007). Sensitivity analysis of transient population dynamics. Ecol. Letters 10,115.

Di Vittorio, M., Ciaccio, A., Grenci, S., \& Luiselli, L. (2015). Ecological modelling of the distribution of the lanner falcon Falco biarmicus feldeggi in Sicily at two spatial scales. Ardeola 62, 81-94. 
1 Dugger, K.M., Anthony, R.G. \& Andrews, L.S. (2011). Transient dynamics of invasive competition: Barred Owls, Spotted Owls, habitat, and the demons of competition present. Ecol. Appl. 21, 2459-2468.

Ferguson-Lee, J \& Christie, D.A. (2001). Raptors: Birds of prey of the world. London: A. \& C. Black Publishing.

Ferraz, G., Nichols, J.D., Hines, J.E., Stouffer, P.C., Bierregaard, R.O \& Lovejoy, T.E. (2007). A large-scale deforestation experiment: effects of patch area and isolation on Amazon birds. Science 315, 238-241.

Fuchs, J., Johnson. J.A. \& Mindell, D.P. (2015). Rapid diversification of falcons (Aves: Falconidae) due to expansion of open habitats in the Late Miocene. Mol. Phylog. Evolution 82, 166-182.

García, J.T. \& Arroyo, B.E. (2002). Intra- and interspecific agonistic behaviour in sympatric harriers during the breeding season. Animal Behav. 64, 77-84.

Gotelli, N.J. \& Entsminger, G.L. (2001). EcoSim: Null models software for ecology. Version 7.0. http://homepages.together.net/ gentsmin/ecosim.htm.

Gotelli, N.J. \& Graves, G.R. (1996). Null models in ecology. Washington, DC: Smithsonian Institution Press.

Gotelli, N.J. \& Mc Cabe, D.J. (2002). Species co-occurrence: a meta-analysis of J. M. Diamond's assembly rules model. Ecology 83, 2091-2096.

Green, A.W., Bailey, L.L. \& Nichols, J.D. (2011). Exploring sensitivity of a multistate occupancy model to inform management decisions. J. Appl. Ecol. 48, 1007-1016.

Hakkarainen, H., Mykrä, S., Kurki, S., Tornberg, R. \& Jungell, S. (2004). Competitive interactions among raptors in boreal forests. Oecologia 141, 420-424.

Hill, M.F., Witman, J.D. \& Caswell, H. (2002). Spatio-temporal variation in Markov chain models of subtidal community succession. Ecol. Letters 5, 665-675.

Hill, M.F., Witman, J.D. \& Caswell, H. (2004). Markov chain analysis of succession in a rocky subtidal community. American Naturalist 164, 46-61.

Hutchinson, G.E. (1959). Homage to Santa Rosalia; or, why are there so many kinds of animals? American Naturalist 93, 145-159.

IUCN (2011). The IUCN Red List of Threatened Species (version 2011.1). www.iucn redlist.org.

Jenkins, J.R. (1995). Morphometrics and Flight Performance of Southern African Peregrine and Lanner Falcons. J. Avian Biol. 26, 49-58. 
1 Jiménez-Franco, M.V., Martínez, J.E. \& Calvo, J.F. (2011). Territorial occupancy dynamics in a forest raptor community. Oecologia 166, 507-516.

3 Krüger, O. (2002a). Analysis of nest occupancy and nest reproduction in two sympatric raptors: common buzzard Buteo buteo and goshawk Accipiter gentilis. Ecography 25, 523-532.

Krüger, O. (2002b). Interactions between common buzzard Buteo buteo and goshawk Accipiter gentilis: trade-offs revealed by a field experiment. Oikos 96, 441-452.

López-López, P., García-Ripollés, C., García-López, F., Aguilar, J.M. \& Verdejo, J. (2004). Distribution pattern among Golden Eagle Aquila chrysaetos and Bonelli's Eagle Hieraaetus fasciatus in the Castellón province. Ardeola 51, 275-283.

López-López, P., Soutullo, A., García-Ripollés, C., Urios, V., Cadahía, L. \& Ferrer, M. (2009). Markov models of territory occupancy: implications for the management and conservation of competing species. Biodiv. Conserv. 18, 1389-1402.

Losos, J.B. (2008). Phylogenetic niche conservatism, phylogenetic signal and the relationship between phylogenetic relatedness and ecological similarity among species. Ecol. Letters 11, 995-1003.

MacKenzie, D.I., Nichols, J.D., Royle, J.A., Pollock, K.H., Bailey, L.L. \& Hines, J.E. (2006) Occupancy Estimation and Modeling: Inferring Patterns and Dynamics of Species Occurrence. Burlington, MA: Academic Press.

Martin, J., McIntyre, C.L., Hines, J.E., Nichols, J.D., Schmutz, J.A. \& Mac Cluskie, M.C. (2009a). Dynamic multistate site occupancy models to evaluate hypotheses relevant to conservation of Golden Eagles in Denali National. Park, Alaska. Biol. Conserv. 142, 2726-2731.

Martin, J., Nichols, J.D., McIntyre, C.L., Ferraz, G. \& Hines, J.E. (2009b). Perturbation analysis for patch occupancy dynamics. Ecology 90, 10-16.

Miller, D.A.W., Brehme, C.S., Hines, J.E., Nichols, J.D. \& Fisher, R.N. (2012). Joint estimation of habitat dynamics and species interactions: disturbance reduces cooccurrence of non-native predators with an endangered toad. J. Animal Ecol. 81, $1288-1297$.

Moreno-Rueda, G., Pizarro, M., Ontiveros, D. \& Pleguezuelos, J.M. (2009). The coexistence of the eagles Aquila chrysaetos and Hieraaetus fasciatus increases with low human population density, intermediate temperature, and high prey diversity. Ann. Zool. Fennici 46, 283-290.

Newton, I. (1979). Population ecology of raptors. London: T. \& A. D. Poyser. 
1 Oro, D., Pérez-Rodríguez, A., Martínez-Vilalta, A., Bertolero, A., Vidald, F. \& Genovart, M. (2009). Interference competition in a threatened seabird community: A paradox for a successful conservation. Biol. Conserv. 142, 1830-1835.

Peronace, V., Cecere, J.G., Gustin, M. \& Rondinini, C. (2012). Lista rossa degli Uccelli d'Italia. Avocetta 36, 11-58.

Roemer, G.W. \& Wayne, R.K. (2003). Conservation in conflict: the tale of two endangered species. Conserv. Biol. 17, 1251-1260.

Santulli, G., Palazón, S., Melero, Y., Gosálbez, J. \& Lambin, X. (2014). Multi-season occupancy analysis reveals large scale competitive exclusion of the critically endangered European mink by the invasive non-native American mink in Spain. Biol. Conserv. 176, 21-29.

Sarà, M. (2008). Breeding abundance of threatened raptors as estimated from occurrence data. Ibis 150, 766-778.

Sarà, M. (2014). Spatial analysis of lanner falcon habitat preferences: Implications for agroecosystems management at landscape scale and raptor conservation. Biol. Conserv. 178, 173-184.

Sarà, M., Campobello, D. \& Zanca, L. (2012). Effects of nest and colony features on lesser kestrel (Falco naumanni) reproductive success. Avian Biol. Res. 5, 209-217.

Sergio, F. \& Newton, I. (2003). Occupancy as a measure of territory quality. J. Animal Ecol. 72, 857-865.

Sergio, F. \& Hiraldo, F. (2008). Intraguild predation in raptor assemblages: a review. Ibis 150, 132-145.

Sokos, C.K., Mamolos, A.P., Kalburtji, K.L. \& Birtsas, P.K. (2013). Farming and wildlife in Mediterranean agroecosystems. J. Nature Conserv. 21, 81-92.

Soulé, M.E., Estes, J.A., Berger, J. \& Martínez del Río, C. (2003). Ecological effectiveness: conservation goals for interactive species. Conserv. Biol. 17, 1238-1250.

Spedicato, G.A. (2015). Markovchain: an R Package to Easily Handle Discrete Markov Chains. R package version 0.0.8.

Tanner, J.E., Hughes, T.P. \& Connell, J.H. (1994). Species coexistence, keystone species and succession in coral assemblages: a sensitivity analysis. Ecology 75, 2204-2219.

Thirgood, S., Redpath, S., Newton, I. \& Hudson, P. (2000). Raptors and Red Grouse: Conservation Conflicts and Management Solutions. Conserv. Biol. 14, 95-104.

Tokeshi, M. (1998) Species Coexistence: Ecological and Evolutionary Perspectives. New York: John Wiley \& Sons. 
1 Waggoner, P.E. \& Stephens, G.R. (1970). Transition probabilities for a forest. Nature 255, $2 \quad 1160-1161$.

3 Ward, A.B., Weigl, P.D. \& Conroy, R.M. (2002). Functional morphology of raptor 4 hindlimbs: Implications for resource partitioning. Auk 119, 1052-1063. 
1 Table 1. Estimated average transition matrix for the lanner falcon (Falco biarmicus feldeggii)

2

3

4

5

6

7 and the peregrine falcon (Falco peregrinus brookei) in Sicily (Italy) resulting from territory-occupancy state transitions observed between 2000 and 2013. Observed frequencies are in parentheses.

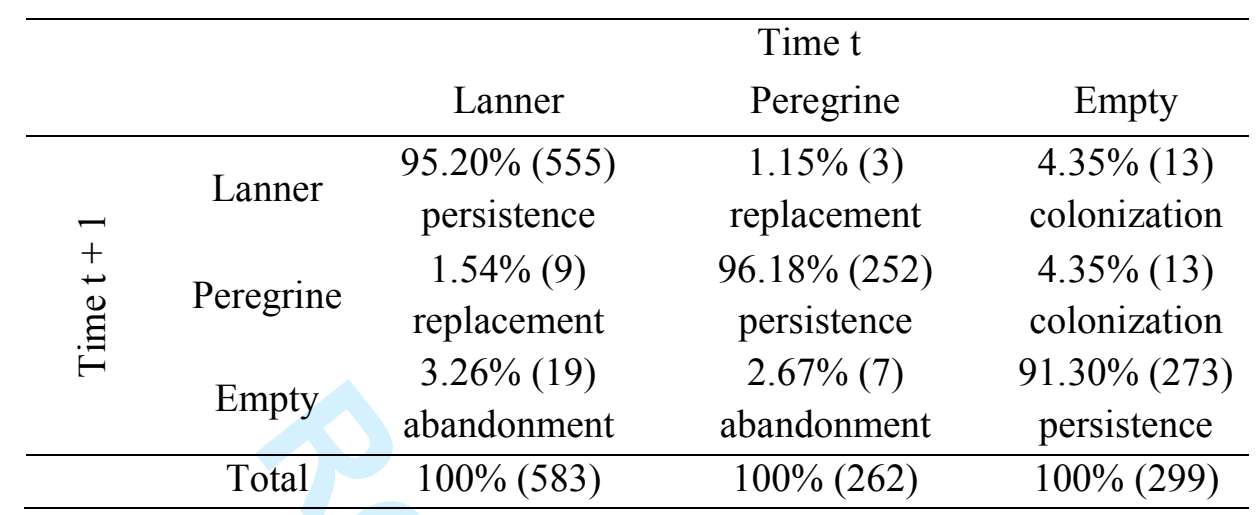


2 Figure 1. Projected changes in the number of territories occupied by lanner falcon, peregrine

3 falcon and vacant territories in Sicily (Italy) according to the baseline scenario obtained from

4 territory-occupancy state transitions observed in 2000-2013.

\section{5}

6 Figure 2. Sensitivity analysis of the Markov chain. Changes were modelled by iteratively

7 increasing the transition probability of the variable of interest to $1 \%, 2.5 \%$ and $5 \%$ (first row

8 of the heading) and consequently decreasing the compensatory variable (second row of the

9 heading). For example, the upper left figure shows the effect of $1 \%$ increase in the transition

10 probability from lanner to lanner compensated by $1 \%$ decrease of the transition probability

11 from lanner to peregrine (LP) or to empty (LE). LL reflects measures aimed at favouring

12 persistence, PL shows an increase in replacement from peregrines to lanners, and EL reflects

13 measures aimed at favouring colonization of empty territories by lanners.

15 Figure 3. Results of elasticity analysis of the transition matrix of the baseline scenario. The

16 figure shows lanner falcon final population size in Sicily under different scenarios.

17 Increasing the probability of lanner falcon: i) colonizing empty territories (empty - lanner);

18 ii) replacing territories occupied by peregrines (peregrine - lanner); and iii) persistence of

19 territories (lanner - lanner). Changes in transitions are similar to those in Fig. 2. Symbols (+)

20 and (-) indicate increase or decrease in the corresponding transition probability. 
Supporting Information

Appendix S1. According to Hutchinson's (1959) seminal intuition, a set of sympatric similar species should be regularly spaced along a size sequence at a constant ratio of 1.3 for length, and 1.5-2.0 for body weight, in order to prevent competition and enable coexistence (Hutchinson \& McArthur, 1959; Diamond, 1975). These size-ratios (namely the Hutchinson ratios, HR: larger/smaller measurement), which gained enormous popularity in zoological literature, lost their appeal because they were found to be inconsistent across guilds and dependent on species-specific variance in morphological traits (Simberloff \& Boecklen, 1981; Wiens, 1982); however they are still a useful way to assess morphological difference and potential competition among species within a guild (e.g., Basset \& Angelis, 2007; Leyequién, de Boer \& Cleef, 2007).

Sympatry is a basic condition for size comparison of species (Wiens, 1982), hence we obtained the body weights (in grams) from literature, and recorded from museum specimens five further body metrics (wing, tail, tarsus, bill lengths plus bill height in mm) of lanner and peregrine living in Sicily, to calculate the respective Hutchinson's (1959) ratios. The 'Size Overlap' module of Ecosim 7.0 was used to assess the size overlap of the two species (Gotelli \& Entsminger, 2001), and the minimum segment length (MLS) to test (independently for each body metrics) the Hutchinson's hypothesis that predicts a critical minimum size separation necessary for coexistence. According to this hypothesis, the observed MSL would be significantly larger than the expected MSL calculated by null simulated distributions. Such null models were obtained by a randomization algorithm over 1000 iterations of raw data. Furthermore, to measure the degree of overlap of falcon traits by the 'Niche Overlap' module of Ecosim 7.0 (Gotelli \& Entsminger, 2001), we used local data of both species (Schenk et al., 1983; Massa et al., 1991; MS and RM unpublished data) for: i) frequency and prey 
biomass in the diet; ii) heights and substrate type of cliffs used during the breeding season; iii) the average Julian day of laying $\left(1^{\text {st }}\right.$ January $\left.=1\right)$. The randomization algorithm was here set to relax the niche breadth and retain the zero states (see Gotelli \& Entsminger, 2001). We selected this latter option because we considered that, besides species interactions, the other explicit constraint could only be the non-utilization of some resources (e.g. non-bird prey for peregrine). Accordingly, we used the default option of an equiprobable distribution of resource states to calculate the Pianka (1973) niche overlap index (PI) from real data and their simulated distributions over 1000 iterations. PI measures the relative amount of resource overlap between two species and ranges from a minimum of 0.0 (no shared resources) to a maximum of 1.0 (identical resource use). The corresponding $P$-value gives the probability that the observed index is not statistically different from that obtained by chance.

\section{References}

Basset, A. \& Angelis, D.L. (2007). Body size mediated coexistence of consumers competing for resources in space. Oikos 116, 1363-1377.

Diamond, J.M. (1975). Assembly of species communities. Ecology and evolution of communities, (eds M.L. Cody \& J.M. Diamond), pp. 342-344. Cambridge: Harvard University Press.

Gotelli, N.J. \& Entsminger, G.L. (2001). EcoSim: Null models software for ecology. Version 7.0. http://homepages.together.net/ gentsmin/ecosim.htm.

Hutchinson, G.E. (1959). Homage to Santa Rosalia; or, why are there so many kinds of animals? American Naturalist 93, 145-159.

Hutchinson, G.E. \& McArthur, R.H. (1959). A theoretical ecological model of size distribution among species of animals. American Naturalist 93, 117-125.

Gotelli, N.J. \& Entsminger, G.L. (2001). EcoSim: Null models software for ecology. Version 7.0. http://homepages.together.net/ gentsmin/ecosim.htm.

Leyequién, E., de Boer, W.F. \& Cleef, A. (2007). Influence of body size on coexistence of bird species. Ecol. Res. 22, 735-741. 
Massa, B., Lo Valvo, F., Siracusa, M. \& Ciaccio, A. (1991). Il Lanario (Falco biarmicus feldeggii Schlegel), in Italia: status, biologia e tassonomia. Naturalista siciliano 15, 27-63.

Pianka, E.R. (1973). The structure of lizard communities. Ann. Rev. Ecol. Evol. System. 4, $53-74$.

Schenk, H., Chiavetta, M., Falcone, S., Fasce, P., Massa, B., Mingozzi, T. \& Saracino, U. (1983). Il Falco pellegrino: indagine in Italia. Parma: Serie Scientifica LIPU.

Simberloff, D. \& Boecklen, W. (1981). Santa Rosalia reconsidered: size ratios and competition. Evolution 35, 1206-1228.

Wiens, J.A. (1982). On size ratios and sequences in ecological communities: Are there no rules? Ann. Zool. Fennici 19, 297-308. 
Table S1. Size overlap test of the Hutchinson's hypothesis about the critical minimum separation necessary for coexistence of lanner and peregrine falcons living in Sicily. If species are separated by a critical minimum, then the observed Minimum Segment length $\left(\mathrm{MSL}_{\mathrm{obs}}\right)$ would be significantly larger than the expected $\left(\mathrm{MSL}_{\mathrm{exp}}\right)$ predicted by the null model. A not significant P-value means that the Hutchinson' hypothesis of a minimum spacing necessary for coexistence is rejected. Peregrine and lanner would thus compete for resources because they have a very similar body size.

Body weight in grams, all lengths measured in $\mathrm{mm} . \mathrm{F}=$ female; $\mathrm{M}=$ male. $\mathrm{HR}=$ Hutchinson ratio. The value of $\mathrm{MSL}_{\exp }$ variance is shown in parentheses.

$\begin{array}{lllllllll}\text { Peregrine falcon } & n & \text { Lanner falcon } & n & \mathrm{HR} & \mathrm{MSL}_{\mathrm{obs}} & \mathrm{MSL}_{\text {exp }} & P\end{array}$

\begin{tabular}{|c|c|c|c|c|c|c|c|c|}
\hline body weight $\mathrm{F}$ & $780.0 \pm 202.0$ & 4 & $882.5 \pm 143.4$ & 4 & 1.1 & \multirow{2}{*}{0.055} & \multirow{2}{*}{$0.028(0.0004)$} & \multirow{2}{*}{0.130} \\
\hline body weight M & $500.0 \pm 131.4$ & 4 & $639.0 \pm 129.0$ & 5 & 1.3 & & & \\
\hline wing length $F$ & $331.2 \pm 7.4$ & 4 & $346.5 \pm 8.2$ & 18 & 1.0 & \multirow{2}{*}{0.019} & \multirow{2}{*}{$0.009(0.00004)$} & \multirow{2}{*}{0.080} \\
\hline wing length $\mathrm{M}$ & $288.3 \pm 12.4$ & 6 & $316.9 \pm 6.1$ & 7 & 1.1 & & & \\
\hline tail length $\mathrm{F}$ & $158.5 \pm 6.6$ & 4 & $185.6 \pm 7.5$ & 13 & 1.2 & \multirow{2}{*}{0.024} & \multirow{2}{*}{$0.014(0.0001)$} & \multirow{2}{*}{0.206} \\
\hline tail length $\mathrm{M}$ & $138.2 \pm 5.6$ & 6 & $167.5 \pm 3.5$ & 6 & 1.2 & & & \\
\hline bill length $F$ & $23.9 \pm 0.8$ & 7 & $22.2 \pm 1.0$ & 16 & 1.1 & \multirow{2}{*}{0.009} & \multirow{2}{*}{$0.010(0.00005)$} & \multirow{2}{*}{0.498} \\
\hline bill length $\mathrm{M}$ & $20.0 \pm 2.3$ & 7 & $19.6 \pm 0.9$ & 7 & 1.0 & & & \\
\hline bill height $F$ & $16.9 \pm 0.8$ & 7 & $17.4 \pm 0.3$ & 5 & 1.0 & \multirow{2}{*}{0.013} & \multirow{2}{*}{$0.008(0.00003)$} & \multirow[b]{2}{*}{0.224} \\
\hline bill height $\mathrm{M}$ & $14.8 \pm 0.6$ & 8 & $15.8 \pm 0.5$ & 4 & 1.1 & & & \\
\hline tarsus length $\mathrm{F}$ & $61.9 \pm 3.8$ & 7 & $53.7 \pm 2.6$ & 16 & 1.0 & \multirow{2}{*}{0.006} & \multirow{2}{*}{$0.009(0.00004)$} & \multirow{2}{*}{0.575} \\
\hline tarsus length $\mathrm{M}$ & $54.5 \pm 1.8$ & 7 & $51.9 \pm 2.2$ & 6 & 1.0 & & & \\
\hline
\end{tabular}


Table S2. Niche overlap test of lanner and peregrine falcons according to the Pianka's index. This index measures the relative amount of resource overlap between each pair of species and ranges from 0 (no shared resources) to1 (identical resource use).

P-values give the probability that the observed index is statistically different from that obtained by chance. In other words, a large Pianka value statistically different from what simulated by chance means that the two species share the same resources and (assuming they are limiting) they should compete for them.

Julian laying day is from Authors unpublished data and B. Massa personal archive. All other data are percentages redrawn from Massa et al. (1991) and Schenk et al. (1983).

Cliff height (m): $A=>50 ; B=50-31 ; C=30-11 ; D=\leq 10$.

Cliff substrate: $\mathrm{A}=$ limestone; $\mathrm{B}=$ conglomerate-sandstone; $\mathrm{C}=$ chalk; $\mathrm{D}=$ lava.

Diet biomass and frequency: $\mathrm{A}=$ Mammals; $\mathrm{B}=$ Birds; $\mathrm{C}=$ Reptiles; $\mathrm{D}=$ Arthropods.

\begin{tabular}{lcccccccccccc}
\hline & \multicolumn{3}{l}{ Peregrine falcon } & \multicolumn{4}{c}{ Lanner falcon } & $\begin{array}{c}\text { Pianka } \\
\text { index }\end{array}$ & $\begin{array}{c}\text { Mean simulated } \\
\text { index (variance) }\end{array}$ & P \\
\hline & A & B & C & D & A & B & C & D & & & \\
Cliff height & 44 & 6 & 0 & 0 & 12 & 24 & 56 & 8 & 0.242 & $0.572(0.045)$ & 0.921 \\
Cliff substrate & 80 & 2 & 16 & 2 & 44 & 28 & 26 & 2 & 0.839 & $0.787(0.023)$ & 0.446 \\
Prey biomass & 0 & 100 & 0 & 0 & 4.4 & 95.1 & 0.2 & 0.3 & 0.999 & $0.437(0.053)$ & 0.000 \\
Prey frequency & 0 & 100 & 0 & 0 & 2.4 & 67.9 & 1.6 & 28.1 & 0.922 & $0.437(0.053)$ & 0.009 \\
Julian laying day & & $137 \pm 9$ & & & $131 \pm 13$ & & 0.390 & $0.465(0.004)$ & 0.867 \\
& & & & & & & & & & & &
\end{tabular}


1

2

3

4

5

6

7

8

9

10

11

12

13

14

15

16

17

18

19

20

21

22

23

24

25

26

27

28

29

30

31

32

33

34

35

36

37

38

39

40

41

42

43

44

45

46

47

48

49

50

51

52

53

54

55

56

57

58

59

60

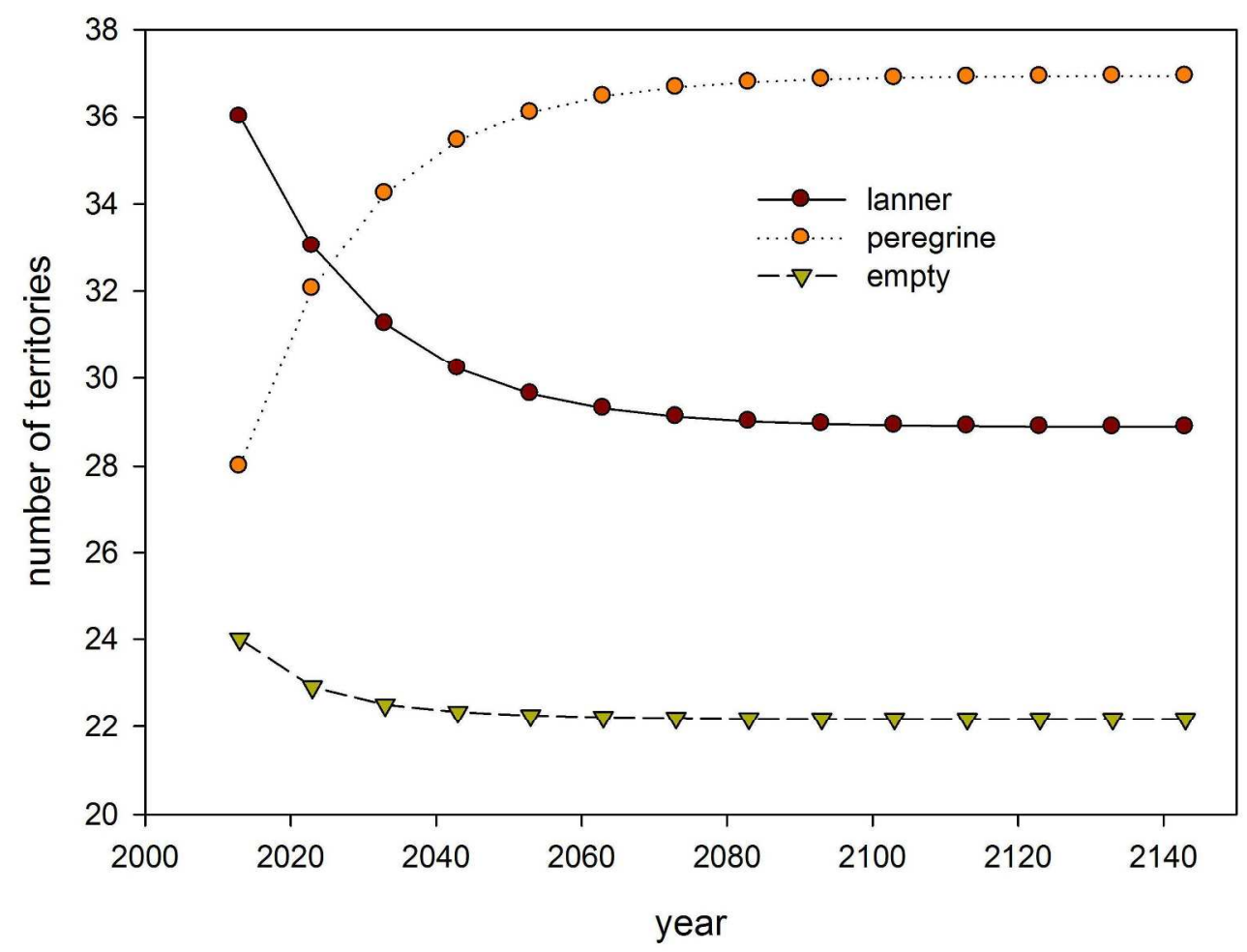

Figure 1. Projected changes in the number of territories occupied by lanner falcon, peregrine falcon and vacant territories in Sicily (Italy) according to the baseline scenario obtained from territory-occupancy state transitions observed in 2000-2013.

$248 \times 188 \mathrm{~mm}(300 \times 300$ DPI) 
Figure 2. Sensitivity analysis of the Markov chain. Changes were modelled by iteratively increasing the transition probability of the variable of interest to $1 \%, 2.5 \%$ and $5 \%$ (first row of the heading) and consequently decreasing the compensatory variable (second row of the heading). For example, the upper left figure shows the effect of $1 \%$ increase in the transition probability from lanner to lanner compensated by $1 \%$ decrease of the transition probability from lanner to peregrine (LP) or to empty (LE). LL reflects measures aimed at favouring persistence, $\mathrm{PL}$ shows an increase in replacement from peregrines to lanners, and EL reflects measures aimed at favouring colonization of empty territories by lanners. $97 \times 43 \mathrm{~mm}(300 \times 300 \mathrm{DPI})$ 
1

2

3

4

5

6

7

8

9

10

11

12

13

14

15

16

17

18

19

20

21

22

23

24

25

26

27

28

29

30

31

32

33

34

35

36

37

38

39

40

41

42

43

44

45

46

47

48

49

50

51

52

53

54

55

56

57

58

59

60

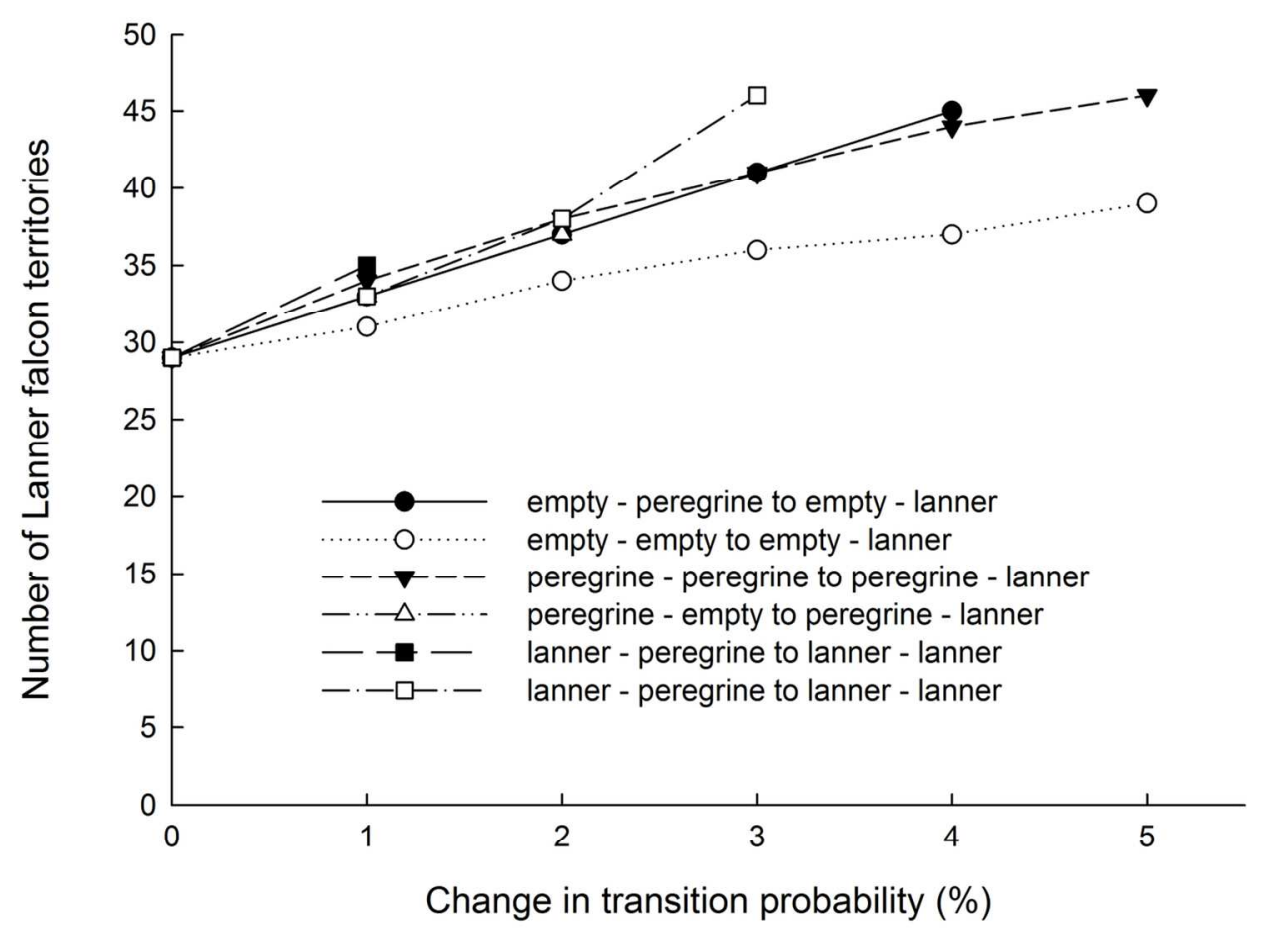

Figure 3. Results of elasticity analysis of the transition matrix of the baseline scenario. The figure shows lanner falcon final population size in Sicily under different scenarios. Increasing the probability of lanner falcon: i) colonizing empty territories (empty - lanner); ii) replacing territories occupied by peregrines (peregrine - lanner); and iii) persistence of territories (lanner - lanner). Changes in transitions are similar to those in Fig. 2. Symbols (+) and (-) indicate increase or decrease in the corresponding transition probability. $123 \times 99 \mathrm{~mm}(300 \times 300$ DPI $)$ 
Peregrine falcon - Falco peregrinus brookei $310 \times 215 \mathrm{~mm}(72 \times 72$ DPI $)$ 